\title{
$\alpha$-Synuclein propagates from mouse brain to grafted dopaminergic neurons and seeds aggregation in cultured human cells
}

\author{
Christian Hansen, ${ }^{1}$ Elodie Angot, ${ }^{1}$ Ann-Louise Bergström, ${ }^{2}$ Jennifer A. Steiner, ${ }^{1}$ Laura Pieri, ${ }^{3}$ \\ Gesine Paul,1 Tiago F. Outeiro,4,5 Ronald Melki, ${ }^{3}$ Pekka Kallunki, ${ }^{2}$ Karina Fog, ${ }^{2}$ \\ Jia-Yi Li, ${ }^{1}$ and Patrik Brundin'1

\begin{abstract}
${ }^{1}$ Neuronal Survival Unit, Wallenberg Neuroscience Center, Lund University, Lund, Sweden. ${ }^{2} \mathrm{H}$. Lundbeck A/S, Valby, Denmark ${ }^{3}$ Laboratoire d'Enzymologie et Biochimie Structurales, CNRS, Gif-sur-Yvette, France. ${ }^{4}$ Cell and Molecular Neuroscience Unit, Instituto de Medicina Molecular, Lisbon, Portugal. ${ }^{5}$ nstituto de Fisiologia, Faculdade de Medicina de Lisboa, Universidade de Lisboa, Lisbon, Portugal.
\end{abstract}

\begin{abstract}
Post-mortem analyses of brains from patients with Parkinson disease who received fetal mesencephalic transplants show that $\alpha$-synuclein-containing ( $\alpha$-syn-containing) Lewy bodies gradually appear in grafted neurons. Here, we explored whether intercellular transfer of $\alpha$-syn from host to graft, followed by seeding of $\alpha$-syn aggregation in recipient neurons, can contribute to this phenomenon. We assessed $\alpha$-syn cell-to-cell transfer using microscopy, flow cytometry, and high-content screening in several coculture model systems. Coculturing cells engineered to express either GFP- or DsRed-tagged $\alpha$-syn resulted in a gradual increase in double-labeled cells. Importantly, $\alpha$-syn-GFP derived from 1 neuroblastoma cell line localized to red fluorescent aggregates in other cells expressing DsRed- $\alpha$-syn, suggesting a seeding effect of transmitted $\alpha$-syn. Extracellular $\alpha$-syn was taken up by cells through endocytosis and interacted with intracellular $\alpha$-syn. Next, following intracortical injection of recombinant $\alpha$-syn in rats, we found neuronal uptake was attenuated by coinjection of an endocytosis inhibitor. Finally, we demonstrated in vivo transfer of $\alpha$-syn between host cells and grafted dopaminergic neurons in mice overexpressing human $\alpha$-syn. In summary, intercellularly transferred $\alpha$-syn interacts with cytoplasmic $\alpha$-syn and can propagate $\alpha$-syn pathology. These results suggest that $\alpha$-syn propagation is a key element in the progression of Parkinson disease pathology.
\end{abstract}

\section{Introduction}

The neuropathological hallmarks of Parkinson disease (PD), Lewy bodies (LB) and Lewy neurites (LN), are intracytoplasmic inclusions that develop in the cell body and neurites of affected neurons, respectively. $\alpha$-Synuclein ( $\alpha$-syn), the primary component of these proteinaceous aggregates (1), is found in most cellular compartments, but enriched in presynaptic terminals (2). $\alpha$-Syn has been suggested to play a role in vesicular transport and neurotransmitter release (3) and to contribute to SNARE complex formation at the presynaptic terminals via a nonclassical chaperone activity (4). An important role for $\alpha$-syn in PD etiology is suggested by observations that inherited PD can arise following 3 missense mutations (5-7) as well as duplication and triplication in the $\alpha$-syn gene $(8,9)$ and that aggregated $\alpha$-syn is abundant in LB and LN also in sporadic PD.

Recently, $\alpha$-syn-positive LB and LN were detected in grafted neurons in PD patients who received transplants of embryonic mesencephalic tissue more than a decade prior to their deaths (10-12). These clinical observations are consistent with the Braak hypothesis; a neurotropic pathogen may cause the spread of LB and LN pathology from a peripheral origin (olfactory bulb, intestine) to the brainstem and finally to more widespread cerebral areas during PD progression (13). $\alpha$-Syn could be such a pathogen that transfers between neurons, contributing to the neuropathological pro-

Authorship note: Christian Hansen and Elodie Angot are co-first authors. Jia-Yi Li and Patrik Brundin are co-senior authors.

Conflict of interest: The authors have declared that no conflict of interest exists. Citation for this article: J Clin Invest. 2011;121(2):715-725. doi:10.1172/JCI43366. gression in PD and to the emergence of LB in grafted embryonic neurons. A so-called prion-like mechanism might underlie the cellto-cell propagation of aggregated $\alpha$-syn (14-18): thus, misfolded $\alpha$-syn could be released from a donor cell, be taken up by a recipient cell, and then seed aggregation of endogenous $\alpha$-syn within that recipient. Both oligomeric and monomeric $\alpha$-syn have been detected in cerebrospinal fluid and plasma samples from both PD patients and control subjects (19-22), suggesting that small aggregates of $\alpha$-syn access the extracellular space. Additionally, $\alpha$-syn monomers and aggregates can be released from cultured cells by exocytosis $(20,23)$ and exosomes have been suggested to participate in this process (24). Recombinant $\alpha$-syn monomers, oligomers, and fibrils have been suggested to be internalized by cultured neuronal cells, either by direct diffusion across the plasma membrane or through an endocytic pathway (25). Interestingly, $\alpha$-syn was recently reported to transfer between neurons in cell culture (26), but a potential seeding effect of $\alpha$-syn aggregation, crucial for putative templating behavior of transmitted $\alpha$-syn, was not addressed. The same study also described $\alpha$-syn transfer between cells in vivo in a transplantation paradigm in the hippocampus. The grafted cells, however, were proliferating stem cells and not postmitotic neurons. Furthermore, this transplantation site differs from the sites of injection in clinical grafting studies and is not a brain region strongly affected by PD (26). Therefore, in vivo transfer of $\alpha$-syn in mature neurons, which are the cells primarily targeted in $\mathrm{PD}$, remained to be demonstrated.

We now report in vivo transfer of $\alpha$-syn to dopaminergic neurons grafted to the striatum of transgenic mice overexpressing human $\alpha$-syn, i.e., a paradigm akin to that of the PD cases exhibiting LB 
A
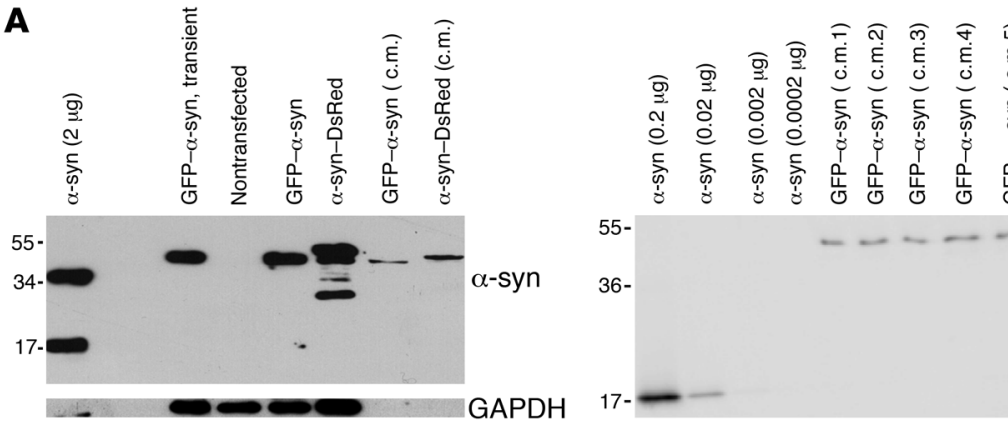

$55-$

36-

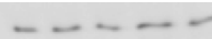

$17-$

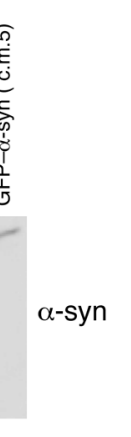

B

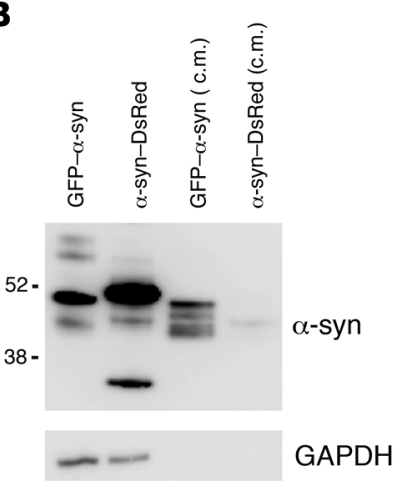

C

厄.<smiles>[TlH]</smiles>

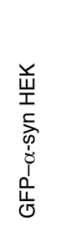

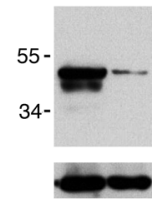

Figure 1

$\alpha$-Syn is secreted into the medium of cultured cells. (A, left) HEK cells not expressing (-) or expressing $\alpha$-syn fused to GFP or DsRed and $30 \mu \mathrm{l}$ of conditioned medium from these cells (c.m.). Expression was compared with $2 \mu \mathrm{g}$ of recombinant $\alpha$-syn. (A, right) Different concentrations of recombinant $\alpha$-syn were compared with conditioned medium from 5 different dishes of GFP- $\alpha$-syn-expressing HEK cells (c.m. 1 to $5)$. The average concentration of $\alpha$-syn in the conditioned medium was estimated at $29 \pm 3 \mathrm{nM}$ ( \pm SEM). (B) SH-SY5Y cells expressing $\alpha$-syn fused to GFP or DsRed and $30 \mu$ l of conditioned medium from these cells. (C) Comparative Western blots showing expression levels of GFP$\alpha$-syn in HEK and SH-SY5Y stable transfectants (left) or in conditioned medium taken from these cells (right). The molecular weights are expressed in $\mathrm{kDa}$ on the left side of the blots. pathology in grafted cells. Moreover, we show that propagated $\alpha$-syn does indeed seed aggregation of $\alpha$-syn in cultured recipient cells. This result suggests that intercellularly transferred $\alpha$-syn may display a prion-like behavior, which could play a central role in the progression of neuropathology in PD.

\section{Results}

Time-dependent $\alpha$-syn transfer in cultured cells. In order to identify and quantify $\alpha$-syn transfer from one cultured cell to another, we produced stable cell lines that express $\alpha$-syn tagged with monomeric fluorescent protein. We generated HEK293 (HEK) and SHSY5Y cell lines that stably express $\alpha$-syn fused to either DsRedmonomer (DsRed) or AcGFP1 (GFP). We readily detected $\alpha$-syn fusion proteins secreted from the HEK cell lines in the culture medium on a polyacrylamide gel (Figure 1A). Using densitometry to compare the levels of GFP- $\alpha$-syn in conditioned medium with different concentrations of recombinant $\alpha$-syn, we found the concentration of GFP- $\alpha$-syn cells to be $29 \pm 3$ nM (mean \pm SEM) in medium exposed to stably transfected HEK cells (Figure 1A). $\alpha$-Syn-GFP-expressing SH-SY5Y cells also secreted $\alpha$-syn-GFP into the medium (Figure 1B), although the amounts were lower than those from GFP- $\alpha$-syn-expressing HEK cells (Figure 1C). $\alpha$-Syn-DsRed-expressing SH-SY5Y cells secreted only low levels of $\alpha$-syn fusion protein (Figure $1 \mathrm{~B}$ ).

When we cocultured HEK cells expressing either $\alpha$-syn-DsRed or GFP- $\alpha$-syn during 5 days, a small percentage of cells exhibited both DsRed and GFP fluorescence, showing that $\alpha$-syn had transferred between the cells (Figure 2A). The double labeling appeared as an evenly diffuse pattern throughout the soma in some cells or as punctate structures in others (Figure 2A). Using confocal microscopy, we confirmed that the transferred $\alpha$-syn fusion protein was located inside the cells (Figure 2B). When we quantified
DsRed/GFP double-labeled cells by FACS, we found that 3\%-4\% and $8 \%-10 \%$ of the cells contained both labels (indicating $\alpha$-syn transfer) after 4 and 7 days, respectively, of coculture (Figure 2, C and D). We repeated the coculture study in differentiated SH-SY5Y cells expressing either $\alpha$-syn-GFP or $\alpha$-syn-DsRed. We detected transfer of $\alpha$-syn-GFP into $\alpha$-syn-DsRed-expressing cells after 8 days of coculture (Supplemental Figure 1; supplemental material available online with this article; doi:10.1172/JCI43366DS1). Moreover, after 14 days of coculture, we found that the internalized $\alpha$-syn-GFP aggregates often colocalized with aggregates of $\alpha$-syn-DsRed, suggesting that $\alpha$-syn can act as a template for aggregation of intracellularly expressed $\alpha$-syn once taken up by cells (Figure 3, A and B). Furthermore, we frequently detected a core of transferred $\alpha$-syn-GFP surrounded by a larger area of endogenous $\alpha$-syn-DsRed, which is consistent with the idea that the transmitted $\alpha$-syn-GFP functioned as a seed for aggregation (Figure 3B). Using high-content screening analysis on 8-day-old cultures, we found that $14.2 \% \pm 8.8 \%$ (mean \pm SD) of the cells were double labeled, thus confirming significant $\alpha$-syn transfer. To determine whether the GFP tag influences $\alpha$-syn transfer and seeding, we incubated $\alpha$-syn-DsRed-expressing SH-SY5Y cells for 22 days in conditioned medium that had been exposed to HEK cells expressing GFP only. Interestingly, the GFP- and GFP$\alpha$-syn-expressing HEK cells secreted comparable amounts of GFP and GFP- $\alpha$-syn (Supplemental Figure 2), respectively. However, only in exceptionally rare cases did we find an SH-SY5Y cell that exhibited some GFP-positive staining, indicative of uptake of GFP from the medium (Supplemental Figure 3). Therefore we conclude that uptake of GFP- $\alpha$-syn is largely $\alpha$-syn driven. In the confocal microscope, we then analyzed the rare cases in which SH-SY5Y cells exhibited GFP staining. We found the GFP punctae to be considerably smaller than the internalized $\alpha$-syn-GFP aggregates. 
A
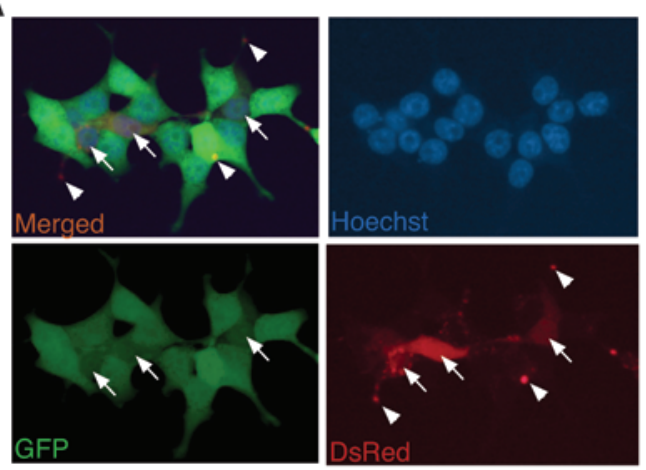

$\mathbf{B}$
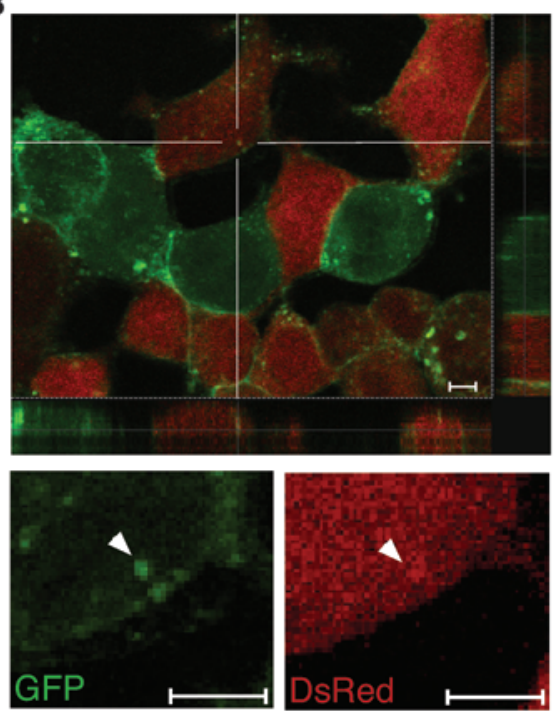

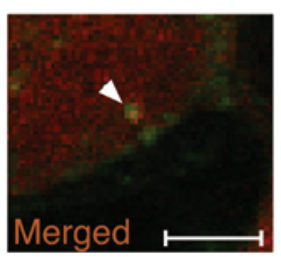

C
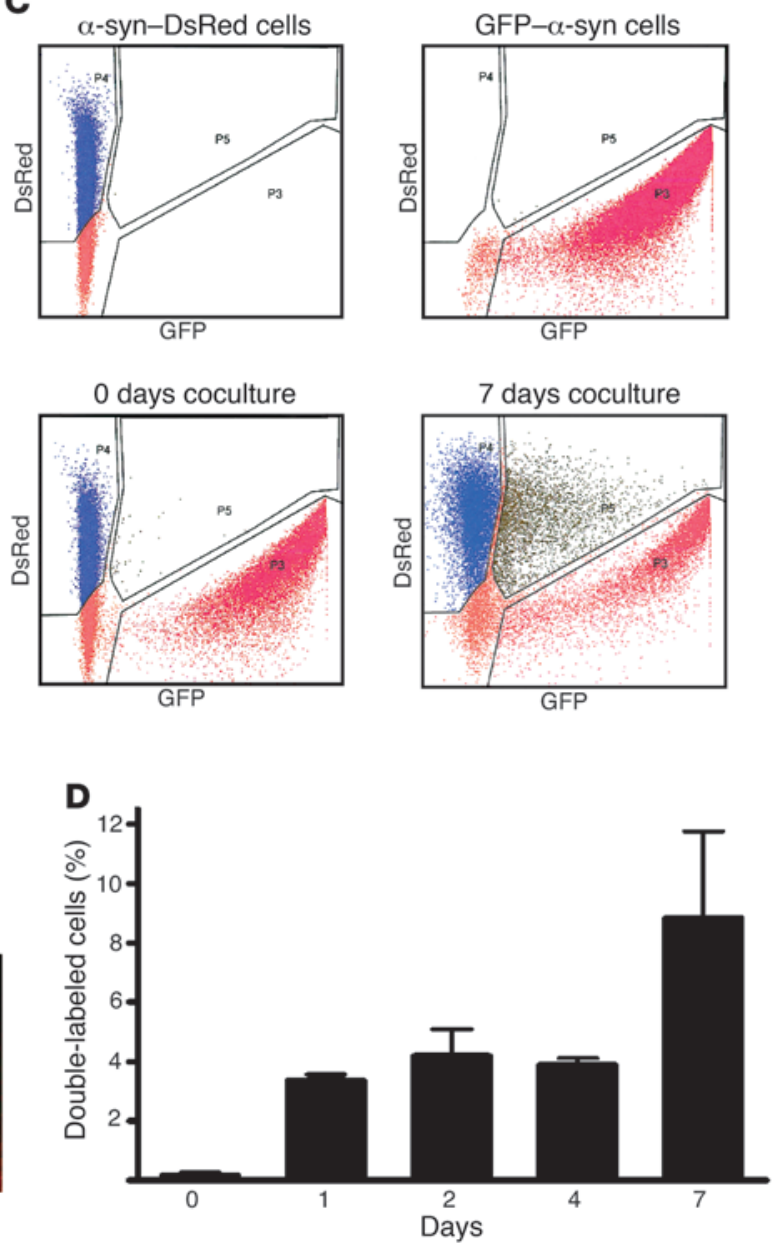

Figure 2

Intercellular propagation of $\alpha$-syn in HEK cell culture. (A) Epifluorescence microscopy: representative picture showing double-labeled HEK cells after 5 days of coculture of stable HEK cell lines expressing $\alpha$-syn fused to either GFP or DsRed. Original magnification, $\times 40$. (B) Confocal microscopy: representative picture showing double-labeled HEK cells after 5 days of coculture of stable HEK cell lines expressing $\alpha$-syn fused to either GFP or DsRed. Scale bars: $5 \mu \mathrm{M}$. Arrows represent double-labeled cells. Arrowheads represent aggregates of transferred $\alpha$-syn. (C) Representative illustrations of $\alpha$-syn transfer between cells as evaluated by FACS analysis. Cells expressing $\alpha$-syn-DsRed or GFP- $\alpha$-syn were analyzed separately (upper panels) and mixed together just prior to the analysis (negative control, lower left panel) or after 7 days of coculture (lower right panel). (D) Quantification from 20,000 cells in FACS analysis after 0, 1, 2, 4, or 7 days of coculture of $\alpha$-syn-DsRed- and GFP$\alpha$-syn-expressing HEK cells $(n=3)$. Error bars represent SD.

Moreover, they never colocalized with intracellularly expressed $\alpha$-syn-DsRed aggregates. These results suggest that the $\alpha$-syn-GFP internalization by $\alpha$-syn-DsRed-expressing cells and subsequent seeding effect we observed in the earlier coculture experiments are specific to $\alpha$-syn and not attributable to the GFP tag.

To confirm that intercellular propagation of $\alpha$-syn is driven by $\alpha$-syn itself, and not by the different tags we have used in our study, we used a human melanoma cell line, SKMel5, which expresses relatively high levels of endogenous $\alpha$-syn (Figure 3C). We cocultured these cells with PC12 rat neuroblastoma cells that stably expressed GFP. After 4 days, we stained the cells with an antibody directed against human $\alpha$-syn and observed distinct transfer of untagged human $\alpha$-syn from the SKMel5 cells to the GFP-expressing PC12 rat cells (Figure 3C). These results were confirmed in coculture of SKMel5 cells with N2a murine neuroblastoma. After 7 days of coculture, the N2a cells, which can be distinguished from the
SKMel5 by staining with antibody against the neuronal marker MAP2, were found to be human $\alpha$-syn positive (Figure 3D), indicating a transfer of untagged human $\alpha$-syn from the SKMel5 cells to the N2a murine cells.

Interaction and aggregation of transferred $\alpha$-syn with intracellular $\alpha$-syn in the recipient cell. Next, we addressed whether transferred $\alpha$-syn can interact with $\alpha$-syn expressed by the recipient cell and form aggregates. We monitored $\alpha$-syn dimerization using a $\alpha$-syn-based BiMolecular Fluorescence Complementation (BiFC) assay (ref. 27 and Figure 4A). The BiFC assay not only reveals whether $\alpha$-syn is transferred between cells, but also shows whether it accesses and binds to intracellularly expressed $\alpha$-syn. As a positive control, we transfected both constructs into the same pool of HEK cells and observed that a large proportion of the cells were GFP positive (Figure 4B). We then used the BiFC assay to evaluate whether $\alpha$-syn cell-to-cell transfer could reconstitute GFP fluorescence. 
A
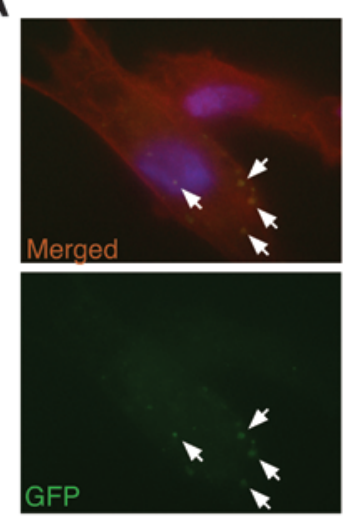

B
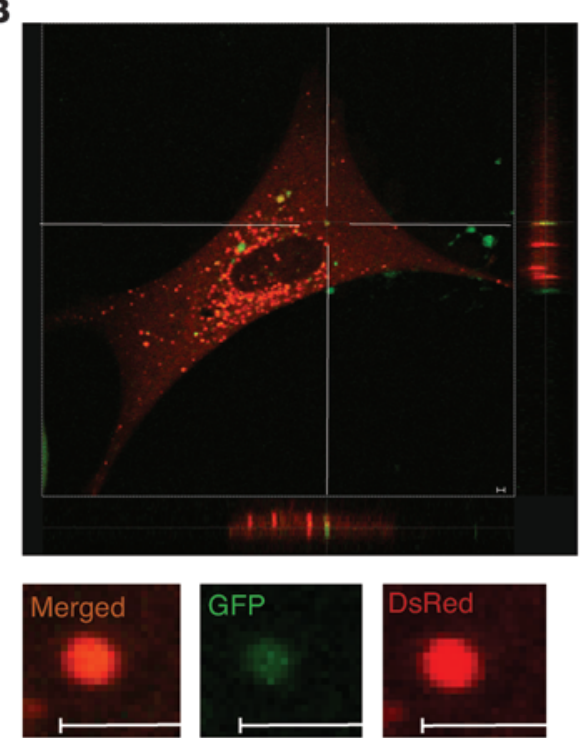
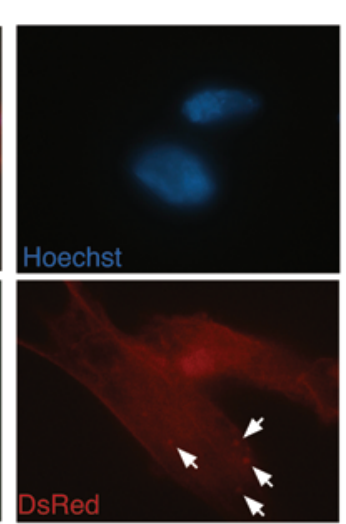

$\mathbf{x}$
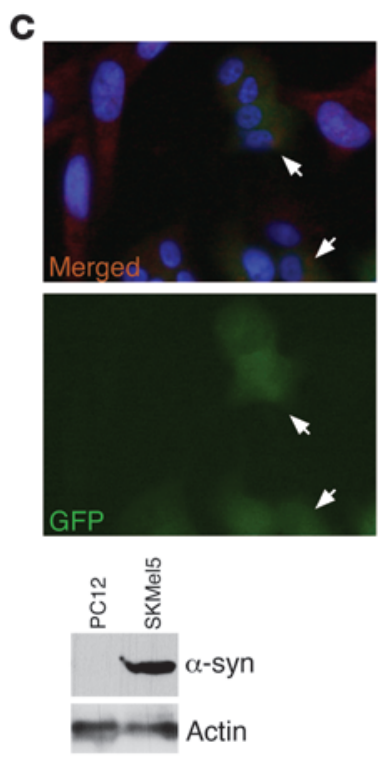

D
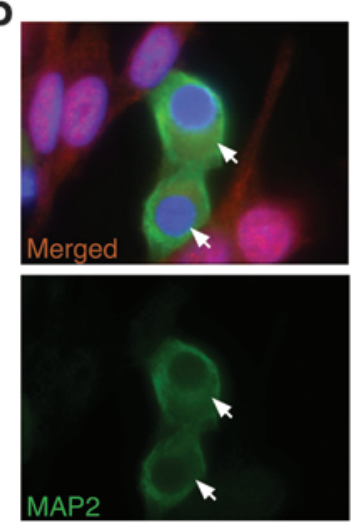
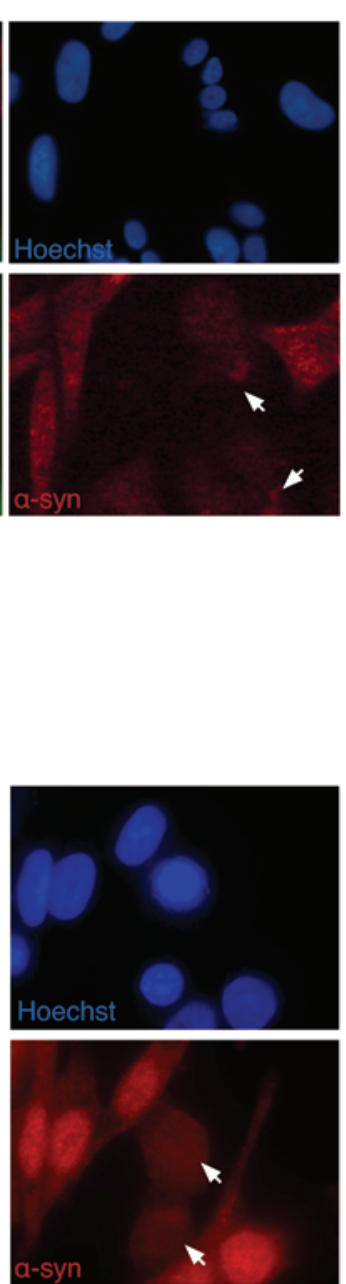

\section{Figure 3}

Intercellular propagation of $\alpha$-syn in SH-SY5Y cell culture. (A) Representative picture showing double-labeled SH-SY5Y cells after 14 days of coculture of stable SH-SY5Y cell lines expressing $\alpha$-syn fused to either GFP or DsRed. Arrows represent transferred aggregates. (B) Confocal microscopy: representative pictures showing double-labeled SH-SY5Y cells after 14 days of coculture of stable SH-SY5Y cell lines expressing $\alpha$-syn fused to either GFP or DsRed. Scale bars: $2 \mu \mathrm{M}$. (C) Upper panel: representative pictures showing double-labeled PC12 cells after 4 days of coculture of human SKMel5 and rat PC12/GFP cells. $\alpha$-Syn was detected with a monoclonal antibody specific for human $\alpha$-syn and an Alexa Fluor 568-coupled secondary antibody directed against mouse. Lower panel: comparative Western blot showing the expression level of $\alpha$-syn in PC12 and SKMel5 cell lysates. Arrows represent double-labeled cells. (D) Representative pictures showing double-labeled N2A cells after 7 days of coculture of human SKMel5 and mouse N2A cells. $\alpha$-Syn was detected with a monoclonal antibody specific for human $\alpha$-syn and a Cy3-coupled secondary antibody directed against mouse, and N2A cells were probed with an antibody specific for MAP2 and an Alexa Fluor 488-coupled secondary antibody directed against rabbit. Arrows represent double-labeled cells. Original magnification, $\times 100$ (A); $\times 40$ (C); $\times 60$ (D).

Thus, we transfected the 2 constructs, encoding nonfluorescent amino- or carboxy-GFP- $\alpha$-syn into 2 different HEK cell populations. We then cocultured these cells 16 hours after changing transfection medium to the growth medium. After 5 days of incubation, we observed GFP-positive cells, indicating an interaction that suggests that transferred $\alpha$-syn had formed dimers with the $\alpha$-syn in recipient cells (Figure $4 C$ ).

In order to address whether intercellular $\alpha$-syn transfer is cellcontact dependent, we cultured naive SH-SY5Y for 5 days in conditioned medium obtained from $\alpha$-syn-DsRed-expressing HEK cells. We observed entry of $\alpha$-syn-DsRed from the conditioned medium into the SH-SY5Y cells, demonstrating that cell contact was not required for $\alpha$-syn transfer. Importantly, thioflavin $S$-positive staining revealed that the transferred $\alpha$-syn-DsRed had adopted an aggregated structure within the cytoplasm of the recipient cell (Figure 4D). These results suggest that a significant proportion of $\alpha$-syn either enters cells in an aggregated form or that it aggregates after entering the recipient cells.

In vivo uptake of recombinant $\alpha$-syn by neuronal cells. Our in vitro data clearly demonstrated that $\alpha$-syn could transfer from one cell to another. Therefore, we next designed in vivo experiments to assess whether this transfer can take place in the mouse brain. We wanted to study which forms of $\alpha$-syn (monomeric, oligomeric, or fibrillar) are taken up by neurons in vivo. To this end, we generated different recombinant $\alpha$-syn species conjugated with Alexa Fluor 488 and characterized them by transmission electron microscopy (Supple- 
A

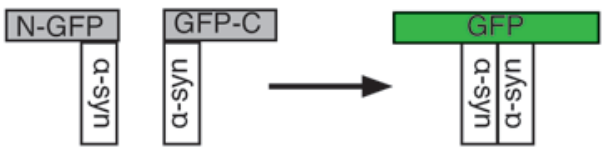

B

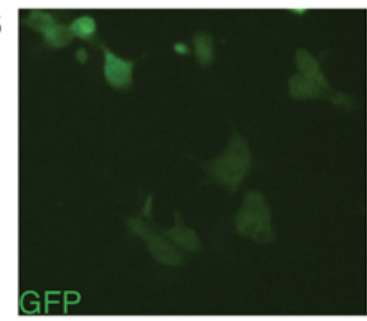

C

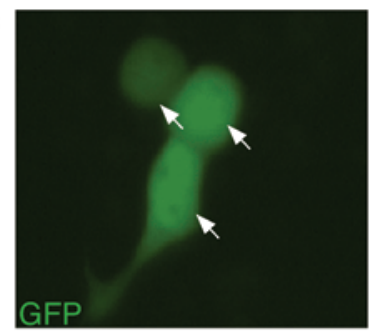

D
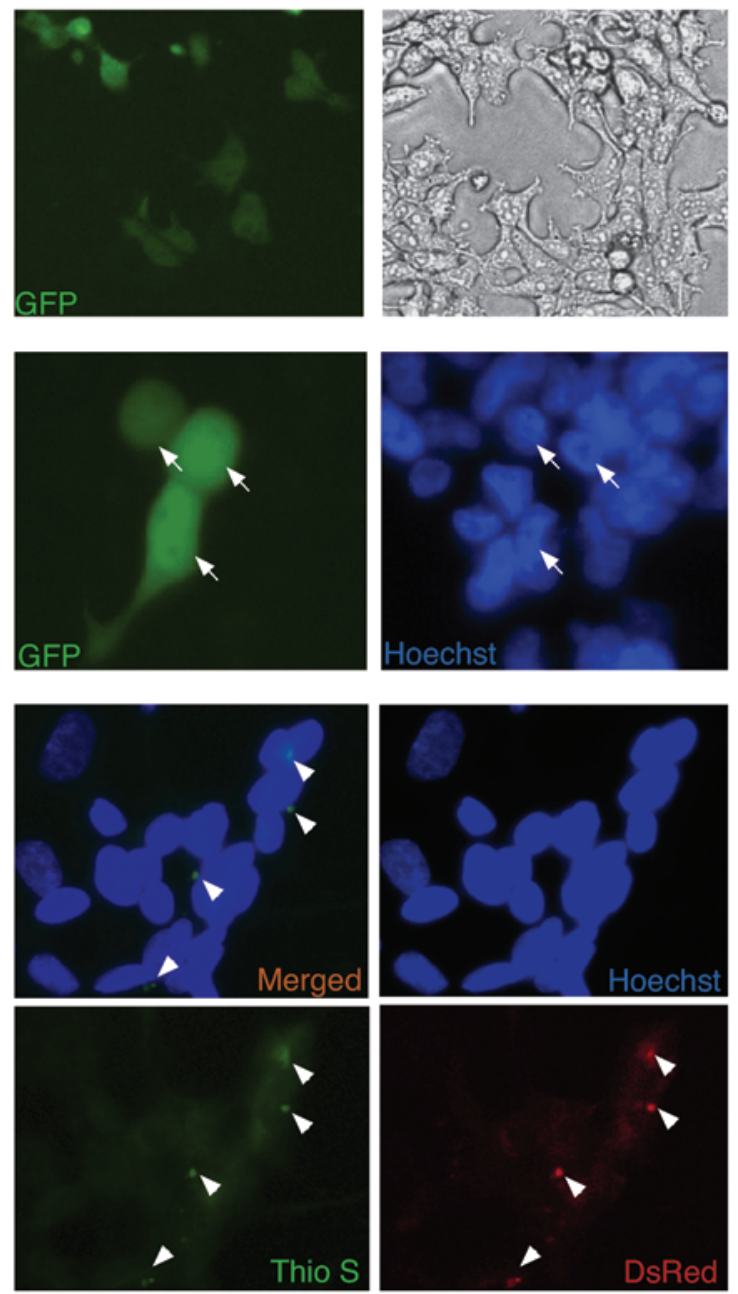

mental Figure 4). Before performing the in vivo experiments, we determined whether cultured cells can take up the different forms of labeled $\alpha$-syn. Furthermore, we verified in vitro that Alexa Fluor 488 labeling of $\alpha$-syn neither altered the capability of the protein to form fibrils nor affected the capacity of the fibrillar form to seed soluble $\alpha$-syn assembly (Supplemental Figure 5). We added $1 \mu \mathrm{M}$ of Alexa Fluor 488-tagged $\alpha$-syn monomers, oligomers, or fibrils to the culture medium of HEK cells. After 3 hours, we detected Alexa Fluor 488 signal within cell bodies in all of the 3 conditions (Figure 5A). These results confirmed that the tagged recombinant $\alpha$-syn species are able to enter cells in vitro. Next, we stereotactically injected Alexa Fluor 488-labeled recombinant $\alpha$-syn proteins into the cortex of 3 groups of mice, which received monomeric, oligomeric, or fibrillar $\alpha$-syn. After 1 day, neurons around the injection site in all 3 groups had taken up Alexa Fluor 488-tagged $\alpha$-syn, as shown by the green fluorescence within the cell body of MAP2positive cells (Figure 5B). Interestingly, we observed that the internalized Alexa Fluor 488-labeled $\alpha$-syn monomers were distributed as a diffuse signal throughout the cell body, whereas aggregated

\section{Figure 4}

Propagated $\alpha$-syn interacts with intracellularly expressed $\alpha$-syn and forms aggregates in recipient cells. (A) Illustration of the $\alpha$-syn-based $\mathrm{BiFC}$ system. Interaction between $2 \alpha$-syn molecules fused to the amino- $(\mathrm{N})$ and carboxyterminal (C) parts of GFP, respectively, leads to reconstitution of GFP fluorescence. (B) HEK cells were transiently transfected with both amino-GFP- $\alpha$-syn expression construct and carboxy-GFP- $\alpha$-syn expression construct serving as a positive control. (C) HEK cells were transiently transfected with either amino-GFP- $\alpha$-syn expression construct or carboxy-GFP- $\alpha$-syn expression construct and coreplated after 16 hours after media change from OPTIMEM transfection medium to DMEM. GFP fluorescence was monitored after 5 days. Arrows represent GFP-positive cells. (D) Conditioned medium from $\alpha$-syn-DsRed-expressing HEK cells was incubated with native $\mathrm{SH}$ SY5Y cells for 5 days. Cells were stained with thioflavin S (0.05\%) and analyzed for $\alpha$-syn-DsRed and aggregate formation by fluorescence microscopy. Arrowheads represent DsRed- and Thioflavin S-positive $\alpha$-syn aggregates. Original magnification, $\times 10$ (B); $\times 40$ (C, D).

forms were detected as fluorescent punctae within the cytoplasm (Figure 5B). These data demonstrate that neurons can take up recombinant $\alpha$-syn proteins regardless of their aggregation state and suggest that the quaternary structure of the proteins is conserved throughout the internalization process.

In vivo transmission of $\alpha$-syn from mouse brain to transplanted dopaminergic neurons. Having demonstrated that $\alpha$-syn injected intracerebrally can enter neurons, we then investigated whether the protein can be transferred from one neuron to another in vivo, as has been suggested by post-mortem studies in PD cases showing LB in grafted mesencephalic neurons $(10,11)$. In order to mimic the clinical situation, we grafted wild-type mouse embryonic mesencephalic neurons into the striatum of mice overexpressing human $\alpha$-syn under the control of the endogenous mouse $\alpha$-syn promoter (Figure 6, A and B). Double immunostaining of striatal sections with antibodies directed against human $\alpha$-syn and tyrosine hydroxylase (TH) allowed us to distinguish clearly the graft-host border. First, the cell bodies labeled with the TH antibody were definitely transplanted neurons, as TH signal in intact striatum is only present in terminals of nigrostriatal dopaminergic neurons whose cell bodies are located in the substantia nigra. Second, the host brain, in contrast with the graft tissue, was strongly human $\alpha$-syn immunoreactive (Figure 6B). After 6 months, we analyzed the transplanted THpositive neurons in detail for human $\alpha$-syn immunoreactivity. We examined more than $400 \mathrm{TH}$-positive cells from 4 grafted human $\alpha$-syn-overexpressing mice with regular epifluorescence microscopy. We selected 92 of them for further analysis, as they showed putative intracellular human $\alpha$-syn-positive punctae, whose precise localization needed to be addressed by confocal microscopy. $3 \mathrm{D}$ reconstructions revealed the presence of intracellular human $\alpha$-syn immunoreactive punctae in 6 of these wild-type grafted dopaminergic neurons (Figure 6, C-E). Interestingly, each of these 6 cells displayed more than 1 (2 to 13 ) transferred human $\alpha$-syn punctae (Supplemental Figure 6), as evidenced by 3D reconstructed rotating images (Supplemental Videos 1 and 2). In summary, our data are consistent with the clinical observations $(10,11)$, as we demonstrate that $\alpha$-syn can be transmitted from host striatal tissue to transplanted dopaminergic neurons.

$\alpha$-Syn propagates between cells in an endocytosis-dependent manner in vitro and in vivo. To address whether an energy-dependent mechanism is involved in $\alpha$-syn uptake, we examined the effects of low temperature. Thus, we treated naive SH-SY5Y cells with concen- 
A
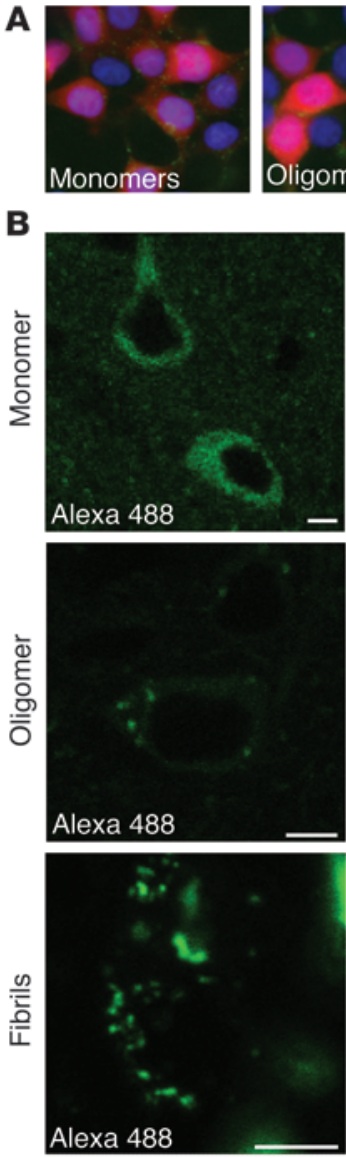
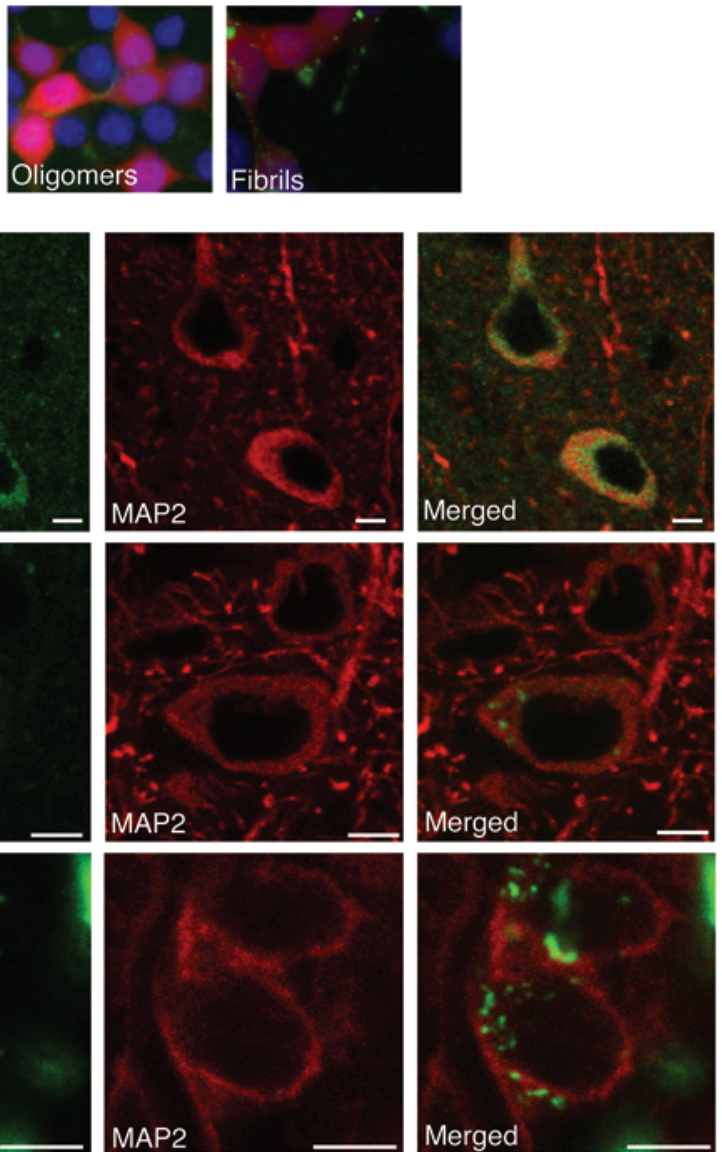

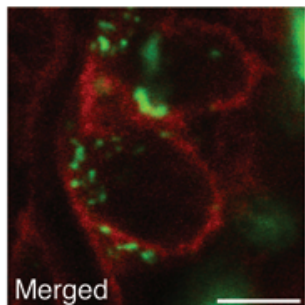

\section{Figure 5}

In vivo entry of recombinant $\alpha$-syn proteins into neuronal cells. (A) 3 hours after addition of $1 \mu \mathrm{M}$ of Alexa Fluor 488-labeled $\alpha$-syn proteins in the culture medium, HEK cells expressing $\alpha$-syn-DsRed have taken up tagged $\alpha$-syn monomers (left), oligomers (middle), and fibrils (right). Original magnification, $\times 40$. (B) Cortical MAP2positive neurons internalized Alexa Fluor 488-labeled $\alpha$-syn monomers (upper panels), oligomers (middle panels), and fibrils (lower panels) after injection into the mouse brain. The left column shows the homogenous distribution of Alexa Fluor 488-labeled (green) monomers throughout the cell body, whereas oligomers and fibrils display a more punctate pattern. The middle column corresponds to the MAP2 staining (red) of recipient neurons and the right column to the merge of left and middle columns. Scale bars: $5 \mu \mathrm{m}$. trated conditioned medium from HEK cells stably expressing GFP- $\alpha$-syn for 6 hours either at $37^{\circ} \mathrm{C}$ or $4^{\circ} \mathrm{C}$. We detected GFP$\alpha$-syn uptake in cells incubated at $37^{\circ} \mathrm{C}$, but not in cells incubated at $4^{\circ} \mathrm{C}$ (Figure $\left.7 \mathrm{~A}\right)$. As lowering the temperature to $4^{\circ} \mathrm{C}$ is known to inhibit endocytic processes, our results suggest that $\alpha$-syn is mainly taken up by cells by endocytosis. To validate this observation, we then cocultured HEK cells expressing $\alpha$-syn tagged with either GFP or DsRed for 3 days in the absence or presence of either monodansylcadaverine (MDC) or dynasore, 2 common endocytosis inhibitors. These inhibitors decreased the number of double-labeled cells by $50 \%$ and $91 \%$, respectively, which supports the notion that endocytosis plays an important role in $\alpha$-syn intercellular transfer (Figure 7B). In determining whether endocytic mechanisms are also involved in cellular uptake of $\alpha$-syn in vivo, we selected the most effective of the 2 endocytosis inhibitors, i.e., dynasore. We coinjected dynasore and Alexa Fluor 488-labeled $\alpha$-syn monomers in the right neocortex of rats. In the neocortex of the left hemisphere of the same animals, we injected Alexa Fluor 488-labeled $\alpha$-syn monomers alone. After 6 hours, we observed large numbers of Alexa Fluor 488-positive neurons around the injection site in the control left cortex (Figure 7C), confirming the uptake of injected $\alpha$-syn monomers by cortical neurons that we previously observed in mice. Importantly, the Alexa Fluor 488 signal was reduced by $40 \%$ in the right cortex where dynasore was coinjected with the labeled $\alpha$-syn monomers (Figure 7, C and D), suggesting that endocytosis contributes significantly to neuronal uptake of $\alpha$-syn monomers in vivo. Taken together, our data strongly support a role for endocytosis in $\alpha$-syn intercellular transfer in vitro and in vivo.

\section{Discussion}

In the present study, we used several cell culture and in vivo models to demonstrate that $\alpha$-syn can propagate between cells and interact with the cytoplasmic pool of $\alpha$-syn in the recipient cell and seed aggregation.

Previous studies have shown that $\alpha$-syn is released $(20,23)$ and taken up (25) by cultured neurons, and transfer of $\alpha$-syn has been demonstrated in SH-SY5Y cells (26). We now provide what we believe is the first evidence for a seeding activity of propagated $\alpha$-syn subsequent to its cell-to-cell transfer in cell coculture system. Such a seeding or nucleation process could constitute a crucial step in putative template-based spreading of $\alpha$-syn pathology. We $(14,15,28)$ and others $(18,29)$ have hypothesized that spreading of misfolded $\alpha$-syn, followed by permissive templating of natively unfolded $\alpha$-syn in the recipient cells, can account for $\alpha$-syn pathology progressively affecting greater parts of the nervous system of PD patients in accordance with Braak neuropathological stages $(13,30)$.

Two observations in our study strongly support the concept that transferred $\alpha$-syn can seed aggregation. First, we saw colocalization of punctae of transferred and intracellularly expressed $\alpha$-syn in SH-SY5Y cells. Second, using confocal microscopy, we found a fraction of imported $\alpha$-syn-GFP nuclei to be enveloped by $\alpha$-syn-DsRed derived from the recipient cell. Interestingly, we only observed this seeding phenomenon in differentiated SH-SY5Y cells, 

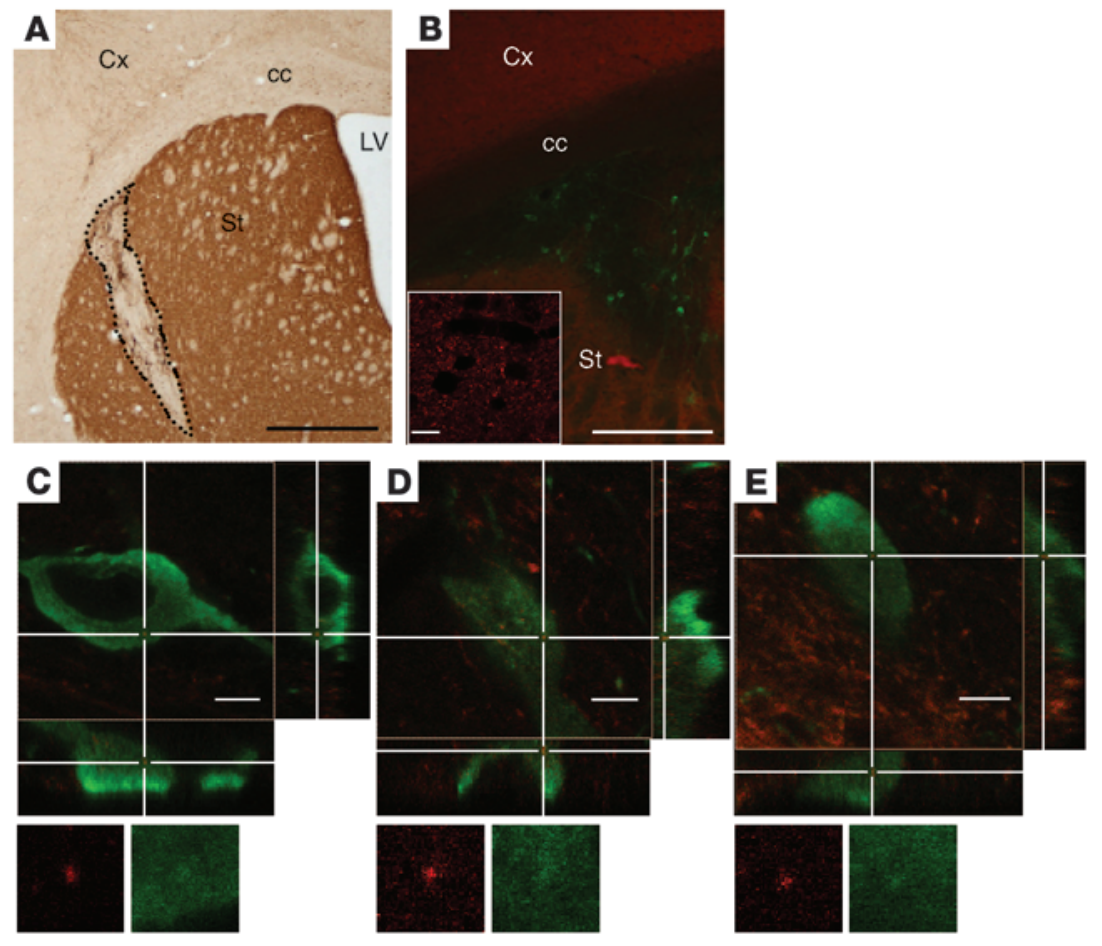

\section{Figure 6}

In vivo transmission of $\alpha$-syn from mouse brain to a graft of dopaminergic neurons. (A) Representative coronal section from grafted human $\alpha$-synoverexpressing mouse stained with an antibody against $\mathrm{TH}$. The dashed line delineates the transplant of TH-positive neurons in the host striatum. (B) Grafted neurons are identified by TH staining (green) within the human $\alpha$-syn-positive (red) striatum of the host. The inset shows high magnification of human $\alpha$-syn-positive accumulations in the host striatum. (C-E) Confocal 3D reconstruction of wild-type TH-positive cells (green) in transgenic mice overexpressing human $\alpha$-syn. The cross points on human $\alpha$-syn-positive dots (red) present within the transplanted cells. Reconstructed orthogonal projections are presented as viewed in the $x-z$ (bottom) and $y-z$ (right) planes. Cx, cortex; cc, corpus callosum; LV, lateral ventricle; St, striatum. Scale bars: 1,000 $\mu \mathrm{m}(\mathbf{A}) ; 500$ $\mu \mathrm{m}(\mathbf{B}) ; 10 \mu \mathrm{m}$ (B, inset); $5 \mu \mathrm{m}$ (C-E). Original magnification, $\times 1915(\mathbf{C}-\mathbf{E})$. but not in HEK cells, which could imply that neurons are more prone to this $\alpha$-syn-dependent nucleation effect, although differences in coculture duration and proliferation state could also play a role. The seeding effect of $\alpha$-syn has previously been suggested, albeit in artificial systems using liposome-based delivery of $\alpha$-syn fibrils (31) or addition of a certain type of recombinant oligomeric $\alpha$-syn to the culture medium at high concentrations (32), in contrast to our more physiologically relevant coculture system. The molecular nature of the $\alpha$-syn "seed" remains unclear. The punctate appearance of internalized $\alpha$-syn in our coculture system, as well as the colocalization of internalized $\alpha$-syn-DsRed and thioflavin S staining in SH-SY5Y cells treated with conditioned medium, shows that the $\alpha$-syn taken up by the cells is largely present in an aggregated form. Furthermore, we report that cortical neurons can take up Alexa Fluor 488-labeled $\alpha$-syn proteins after injection in the mouse brain, regardless of the aggregation state. We confirmed these observations in cell culture, showing that it is mechanistically possible for all 3 forms (monomeric, oligomeric, and fibrillar) of $\alpha$-syn to be internalized by cells. Our ongoing follow-up studies will determine whether this neuronal uptake of recombinant $\alpha$-syn triggers aggregation of endogenous $\alpha$-syn. The fact that both soluble and aggregated $\alpha$-syn are taken up by cells suggests 2 possible mechanisms whereby $\alpha$-syn is observed as visible aggregates in the recipient cells. Thus, $\alpha$-syn may "travel" from one cell to another either as small aggregates or as monomers that progressively accumulate and fibrillize in the recipient cells. The techniques used in our experimental paradigms do not allow us to establish whether the transferred $\alpha$-syn is misfolded at the time of entry to a cell. It remains possible that natively unfolded $\alpha$-syn after entry into a recipient cell adds to the total load of endogenous $\alpha$-syn and thereby saturates the cellular folding machinery that maintains a-syn in the conformation(s) this polypeptide typically adopts in healthy cells. Such changes in cellular proteostasis
(33) could certainly lead to the aggregation of both imported and endogenous $\alpha$-syn, given the propensity of $\alpha$-syn to assemble into high-molecular-weight oligomers. Changes in cellular proteostasis following uptake of exogenous $\alpha$-syn and the seeding activity of transferred misfolded $\alpha$-syn might operate hand-in-hand and thereby contribute to $\alpha$-syn aggregation in the cell-culture paradigms we have studied.

We demonstrated for what we believe is the first time $\alpha$-syn transfer between mature neurons in a clinically relevant grafting paradigm, i.e., from the striatum of transgenic mice to grafted fetal dopaminergic neurons. One can speculate that the relatively small sized transferred human $\alpha$-syn punctae in our grafting experiments represent early seeds that can continuously recruit endogenous $\alpha$-syn from the grafted cells and form larger aggregates over time. This hypothesis is in accordance with a recent study by Chu and Kordower on fetal nigral transplants into PD patients. It demonstrates that $\alpha$-syn immunoreactivity is absent in 18-month-old human nigral grafts, but detectable in a cytoplasmic, nonaggregated form in 4-year-old implants, progressing to $\alpha$-syn-positive LB and LN at 14 years after transplantation (34). Indeed, the initial post-mortem reports on LB and $\mathrm{LN}$ in grafted neurons in PD were made in patients who died more than a decade after transplantation $(10,11)$.

In addition to prion-like spread of $\alpha$-syn from the host to the graft tissue, other mechanisms have been proposed to explain the emergence of LB and LN in grafted neurons in PD brains, such as inflammation or a high degree of oxidative stress in the environment (28). It is therefore important to develop animal models of this grafting paradigm to help resolve the underlying molecular mechanisms. Recently, Desplats and coworkers (26) reported human $\alpha$-syn transfer from a transgenic mouse brain to a graft of mouse neural stem cells. Although this report demonstrated human $\alpha$-syn transfer, the transplantation site (hippocampus) and the nature of the grafted cells (proliferating stem cells) dif- 
A

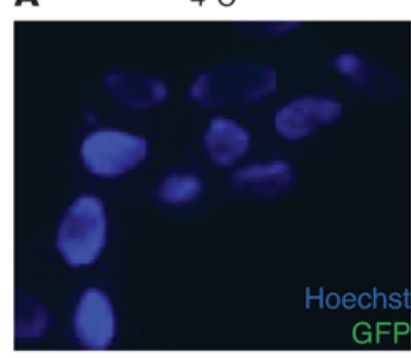

C

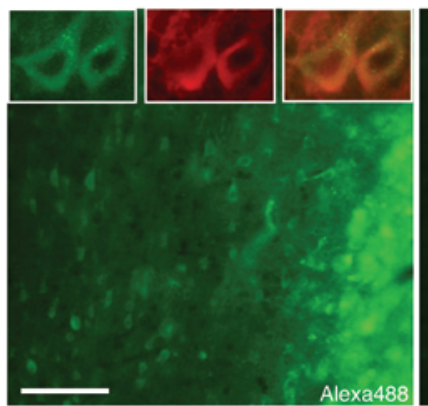

$37^{\circ} \mathrm{C}$

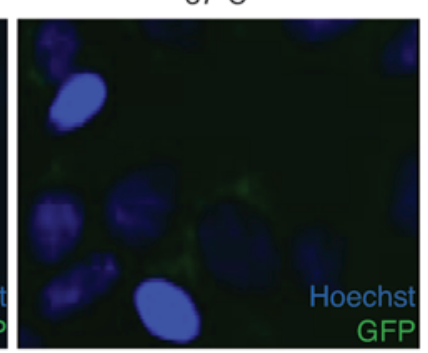

Dynasore

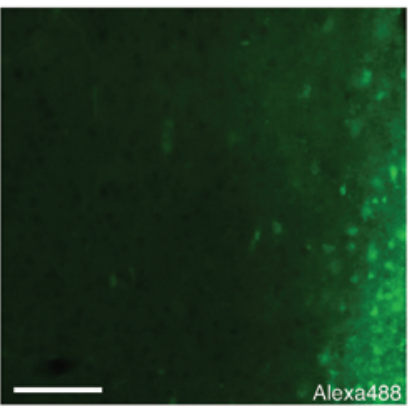

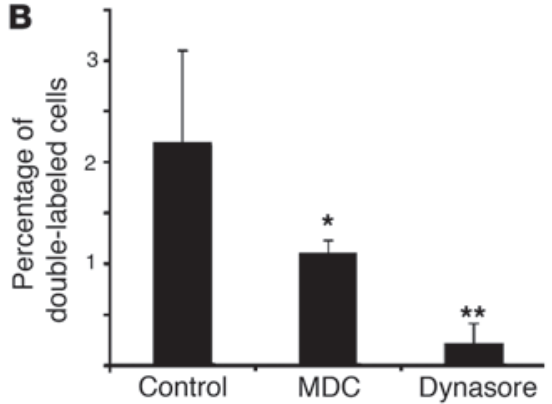

D

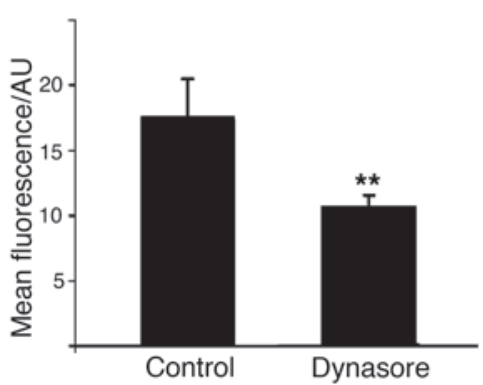

\section{Figure 7}

Inhibition of endocytosis decreases $\alpha$-syn cellular uptake in vitro and in vivo. (A) Conditioned medium from GFP- $\alpha$-syn-expressing HEK cells was concentrated 10 times and incubated with native SH-SY5Y cells at $4^{\circ} \mathrm{C}$ or $37^{\circ} \mathrm{C}$. After 6 hours, GFP $\alpha$-syn uptake was analyzed by fluorescence microscopy. Original magnification, $\times 40$. (B) HEK cells stably transfected with either DsRed- or GFP-tagged $\alpha$-syn were cocultured for 3 days in the absence (control) or presence of the endocytosis inhibitors monodansylcadaverine (MDC, $1 \mu \mathrm{M})$ or dynasore $(1 \mu \mathrm{M})$, and intercellular transfer was evaluated as percentage of double-labeled cells with epifluorescence microscopy $(n=3)$. (C) Alexa Fluor 488 signal detected in cortical sections of the same rat injected with Alexa Fluor 488-labeled $\alpha$-syn monomers on the left side (control) and Alexa Fluor 488-labeled $\alpha$-syn monomers together with dynasore $(80 \mu \mathrm{M})$ on the right side (dynasore). The inset in the control picture shows higher magnification of Alexa Fluor 488-positive cells (green), identified all around the injection site of Alexa Fluor 488-labeled $\alpha$-syn alone. The neuronal nature of these cells is confirmed by colocalization with MAP2 (red). Scale bars: $50 \mu \mathrm{m}$. Original magnification, $\times 60$ (top left panels). (D) The mean Alexa Fluor 488 fluorescence per area unit (AU) measured in the injection site, reflecting cellular uptake as a large majority of extracellular Alexa Fluor $488 \alpha$-syn monomers, is likely to have been degraded after 6 hours and is decreased by $40 \%$ in the dynasore-injected cortex compared with the control side, confirming the inhibition of cellular uptake of Alexa Fluor 488-labeled $\alpha$-syn monomers in the presence of dynasore. Error bars represent SD. ${ }^{\star} P<0.05 ;{ }^{* *} P<0.01$.

fered significantly from the conditions that applied in the clinical PD trials. To mimic the clinical situation more closely, we grafted fetal dopaminergic neurons at a developmental stage when they are largely postmitotic (35) into the striatum of mice overexpressing human $\alpha$-syn. These differences in experimental design and the different choice of promoter-driving $\alpha$-syn expression may explain why the rate of $\alpha$-syn transfer in our model was lower (less than $5 \%$ of grafted cells displayed $\alpha$-syn immunoreactivity after 6 months) compared with that reported in Desplats and coworkers' study (15\% after 4 weeks) (26).

Our results support a role for intercellular $\alpha$-syn transfer and seeding activity in PD progression similar to what has been proposed for other neurodegenerative proteinopathies. Recently, it was shown that recombinant fibrillar polyglutamine (polyQ) peptides seed the aggregation of intracellularly expressed cyan fluorescent protein-tagged huntingtin protein with an extended polyQ tract (36). This study suggests that a seeding mechanism might underlie the propagation of huntingtin inclusions during the progression of Huntington disease. In another study, Frost and coworkers demonstrated that extracellular Tau aggregates can be internalized by cultured murine neuronal precursor cells and trigger the fibrillization of intracellular Tau (37). The seeding capacity of Tau has been dem- onstrated in vivo, in experiments involving intracerebral injections of brain extracts from mice expressing a pathogenic mutation of Tau protein (38). Thus, hyperphosphorylated Tau inclusions might spread via cell-to-cell transfer and trigger nucleation/aggregation in Alzheimer disease and other tauopathies (16).

In conclusion, we provide compelling in vitro and in vivo evidence that $\alpha$-syn can transfer between cells and seed the assembly of soluble $\alpha$-syn. This mechanism might be crucial during PD progression. Consequently, future discovery of drugs that stop, reduce, or delay the systematic spread of $\alpha$-syn toxic species throughout the brain may lead to a new generation of diseasemodifying therapeutics for PD.

\section{Methods}

\section{Cell lines, reagents, plasmids, and transfection}

HEK, SH-SY5Y, SKMel5, and cocultured SKMel5 and N2a cells were grown in DMEM (Sigma-Aldrich) plus 10\% FBS (Sigma-Aldrich) and penicillin/ streptomycin (P/S). PC12 cells stably expressing GFP (a gift from David Rubinsztein, Cambridge Institute for Medical Research, Cambridge, United Kingdom) and cocultured PC12 and SKMel5 cells were grown in RPMI 1640 plus $10 \%$ horse serum plus 5\% FBS. The $\alpha$-syn-GFP and $\alpha$-syn-DsRed 
expression vectors were generated by inserting human $\alpha$-syn cDNA, amplified by primers with flanking XhoI and SacII sites, into the corresponding sites of the PAcGFP1-C1 and pDsRed-monomer-N1 vectors (Clontech), respectively. The pSYN-EGFH2 and pEGFH1-SYN constructs needed for the BiFC assay were designed as previously described (27). For plasmid transfection, cells were transiently transfected using Lipofectamine 2000 according to the manufacturer's protocol (Invitrogen). The endocytosis inhibitors MDC and dynasore were both purchased from Sigma-Aldrich.

\section{Western blotting}

For Western blotting, cells were lysed directly in $1 \times$ Laemmli buffer and boiled for 20 minutes. Proteins were separated on $10 \%$ polyacrylamide gels and subjected to Western blot transfer. Primary antibodies used for Western blotting were mouse anti- $\alpha$-syn (BD Bioscience) and mouse anti-GAPDH (Chemicon). The secondary antibody used was sheep antimouse (GE Healthcare).

\section{Immunofluorescence microscopy}

HEK cell coculture. HEK cells stably expressing $\alpha$-syn-DsRed or GFP- $\alpha$-syn were cocultured for 5 days in chamber culture slides (Nunc). The cells were subsequently stained with Hoechst and fixed in $4 \%$ paraformaldehyde (PFA) and finally mounted with PVA DABCO mounting medium (Sigma-Aldrich). Cell-to-cell transfer was analyzed by epifluorescence using a Nikon Eclipse $80 \mathrm{i}$ microscope. For the studies with endocytosis inhibitors, the HEK cells stably expressing DsRed- or GFP-tagged $\alpha$-syn fusion proteins were allowed to adhere overnight after coreplating. The cell cultures were subsequently incubated with or without endocytosis inhibitors for 3 days. HEK cells transiently transfected with the PSYN-EGFH2 and pEGFH1-SYN BiFC constructs were analyzed in a similar manner. For confocal microscopic analysis, the cells were grown and fixed as above and analyzed by a Leica TCS SL microscope equipped with GreNe and HeNe lasers.

SKMel5 plus PC12/GFP cell coculture. SKMel5 cells and PC12 cells stably expressing GFP were cocultured for 4 days in chamber culture slides (Nunc). The cells were then stained with Hoechst, fixed in 4\% PFA, and washed in PBS before permeabilization with $0.5 \%$ Triton X-100 for 5 minutes. Subsequently, the slides were washed in PBS, blocked for 1 hour in 3\% BSA in PBS, and incubated with antibody directed against human $\alpha$-syn (Abcam) in 3\% BSA in PBS for 1 hour at room temperature. The slides were then washed in PBS, incubated with Alexa Fluor goat anti-rabbit 568 (Invitrogen), washed in PBS, and finally mounted with PVA DABCO mounting medium. Cell-to-cell transfer was analyzed by epifluorescence using a Nikon Eclipse 80i microscope.

SKMel5 plus N2a cell coculture. The SKMel5 and N2a cells were grown in coculture for up to 7 days and fixed at days 1, 4, and 7 in 4\% PFA after a short rinse in PBS. The cells were then permeabilized and blocked as described above and probed with a mouse monoclonal antibody directed against human $\alpha$-syn (Abcam) and a rabbit polyclonal antibody directed against MAP2 (Chemicon). After rinsing, the cells were incubated with a Cy3-coupled secondary antibody against mouse (Jackson) and Alexa Fluor 488-coupled against rabbit (Invitrogen) together with Hoechst. The cells were rinsed and mounted in anti-fading solution (DAKO) and analyzed with a Nikon Eclipse E1000 microscope.

SH-SY5Y cell coculture. SH-SY5Y cells stably expressing either $\alpha$-synDsRed or $\alpha$-syn-GFP were cocultured on polylysine-coated coverslips for up to 25 days in DMEM plus Glutamax with G418 (0.2 mg/ml), 10\% FCS, and $\mathrm{P} / \mathrm{S}$. For the first 14 days of coculture, the cells were differentiated with $50 \mu \mathrm{M}$ retinoic acid. At different time points, cells were fixed with $4 \%$ PFA, counterstained with Hoechst, and mounted in antifade mounting solution (DAKO). Transfer was analyzed by epifluorescence with a Nikon Eclipse E1000 microscope.

\section{Addition of conditioned media to SH-SY5Y cells}

HEK cells stably expressing $\alpha$-syn-DsRed or GFP- $\alpha$-syn or transiently expressing GFP were cultured as above. For production of conditioned media, the cells were grown in serum-free media for 24 hours; then the medium was removed, passed through a $0.22-\mu \mathrm{M}$ filter, and concentrated using a centrifugal YM-10 filter device from Millipore. The conditioned medium was then added to SH-SY5Y cells, and when cells were incubated with conditioned medium for multiple days, fresh conditioned medium was added 2 to 3 times a week. The concentration of the tagged $\alpha$-syn in the conditioned media was adjusted to be around $50 \mathrm{nM}$ for the experiments that lasted over multiple days. To monitor the uptake of GFP- $\alpha$-syn from conditioned medium into SH-SY5Y cells after 6 hours at 4 or $37^{\circ} \mathrm{C}$, conditioned medium from HEK cells expressing GFP$\alpha$-syn was concentrated 10 times via a YM-30 filter (Millipore).

\section{High-content cell morphological screening: analysis}

SH-SY5Y $\alpha$-syn-DsRed and $\alpha$-syn-GFP lines were seeded at 10,000 cells/ well in 96-well plates (thin bottom; Costar) and differentiated as above. At different time points, the cells were fixed and counter-stained as above. The plates were then scanned on a Thermo Scientific Cellomics Array Scan VTI HCS reader using the compartmental analysis algorithm.

\section{Thioflavin S staining}

Cells were fixed and rinsed with PBS and incubated with thioflavin S (T1892, used as a $0.05 \%$ solution in PBS; Sigma-Aldrich) for 10 minutes at room temperature (RT), followed by $3 \times 5$-minute washes in $80 \%$ ethanol, then dehydrated, counterstained with Hoechst (in PBS) for 20 minutes at RT, and mounted with DAKO antifade solution.

\section{FACS measurements}

HEK cells stably expressing $\alpha$-syn-DsRed or GFP- $\alpha$-syn were plated and cocultured for 1 to 7 days in 6-well plates (seeded with a density that would make them subconfluent on the day of FACS analysis). Cells were detached by trypsinization, washed with PBS, mechanically dissociated into singlecell suspension by pipetting and by passing through a $70-\mu \mathrm{m}$ cell strainer (BD Bioscience), and finally resuspended in PBS plus 3\% FBS for FACS analysis on a DiVa FACS sorter (BD).

\section{Animals}

Transgenic mice expressing human wild-type $\alpha$-syn under the control of a 7-kb fragment of the mouse $\alpha$-syn promoter (hu $\alpha$-syn expressing mice) were developed by Lundbeck (39). 6- to 14-week-old transgenic mice were used. Sprague-Dawley female rats ( $225 \mathrm{~g})$ were purchased from Charles River Laboratories. The mice and the rats were housed, respectively, 2 to 6 per cage under a 12 -hour light/12-hour dark cycle with ad libitum access to food and water. The housing of the animals and all procedures were carried out in accordance with international guidelines and were approved by the Malmö-Lund Ethical Committee for Animal Research.

\section{Alexa Fluor 488-labeled $\alpha$-syn recombinant protein production}

Recombinant wild-type $\alpha$-syn was expressed in E. coli strain BL21(DE3) (Stratagene) and purified as described (40). $\alpha$-Syn concentration was determined from the absorbance at $280 \mathrm{~nm}$ using an extinction coefficient of $5960 \mathrm{M}^{-1} \mathrm{~cm}^{-1}$. Pure $\alpha$-syn $(400 \mu \mathrm{M})$ in $20 \mathrm{mM}$ Tris- $\mathrm{HCl}, \mathrm{pH} 7.5,150 \mathrm{mM}$ $\mathrm{NaCl}, 1 \mathrm{mM}$ EGTA, $5 \mathrm{mM} \beta$-mercaptoethanol at $37^{\circ} \mathrm{C}$ was assembled under orbital agitation ( $600 \mathrm{rpm})$. Assembly was monitored by thioflavin $\mathrm{T}$ binding (41) using a Varian Cary Eclipse spectrofluorometer (Varian Inc.) and the nature of the oligomeric species assessed using a Jeol 1400 transmission electron microscope following adsorption onto carbon-coated 200-mesh grids following negative staining with $1 \%$ uranyl acetate. The images were recorded with a Gatan Orius CCD camera (Gatan). 
Monomeric and fibrillar $\alpha$-syn in $50 \mathrm{mM}$ PIPES, $\mathrm{pH}$ 7.5, were labeled by addition of 2 molar excess of the aminoreactive fluorescent dye Alexa Fluor 488 carboxylic acid, succinimidyl ester (Invitrogen). Labeling was performed following the manufacturer's recommendations. Unreacted dye was removed by gel filtration through Illustra NAP-10 columns (GE Healthcare) equilibrated in $50 \mathrm{mM}$ PIPES, $\mathrm{pH} 7.5$, for soluble $\alpha$-syn, followed by 3 cycles of sedimentation and resuspension of the fibrils in $50 \mathrm{mM}$ PIPES, $\mathrm{pH} 7.5$, for fibrillar $\alpha$-syn. Labeled oligomers were formed by overnight incubation at $4^{\circ} \mathrm{C}$ of labeled monomers.

\section{Stereotactic injection of $\alpha-$ syn recombinant proteins}

Stock solutions of Alexa Fluor 488-labeled $\alpha$-syn proteins (monomers, oligomers, fibrils) were diluted with $0.9 \% \mathrm{NaCl}$ to a concentration of 10 $\mathrm{ng} / \mu \mathrm{l}$. Eleven to fourteen-week-old huo-syn-expressing mice were injected using a glass capillary attached to a $10-\mu l$ Hamilton microsyringe with $2 \mu \mathrm{l}$ of these solutions ( $n=3$ in each group) in the right cortex (coordinates, AP: $0.4 \mathrm{~mm}$; ML: $-1.3 \mathrm{~mm}$; DV: $-0.6 \mathrm{~mm}$ relative to bregma and dural surface).

\section{Stereotactic coinjection of $\alpha$-syn recombinant $\alpha$-syn monomers and dynasore}

Stock solution of Alexa Fluor 488-labeled $\alpha$-syn monomers was diluted with $0.9 \% \mathrm{NaCl}$ to a concentration of $1 \mathrm{mg} / \mathrm{ml}$ or codiluted together with the stock solution of dynasore ( $1 \mu \mathrm{M}$ in DMSO) to reach a concentration of $1 \mathrm{mg} / \mathrm{ml}$ for Alexa Fluor 488-labeled $\alpha$-syn monomers and $80 \mu \mathrm{M}$ for dynasore. Three Sprague-Dawley female rats (Charles River Laboratories) were injected using a 10- $\mu \mathrm{l}$ Hamilton microsyringe with $2 \mu \mathrm{l}$ of Alexa Fluor 488-labeled $\alpha$-syn monomers $(1 \mathrm{mg} / \mathrm{ml})$ in the left cortex (coordinates, AP: $1 \mathrm{~mm}$; ML: $2.5 \mathrm{~mm}$; DV: $-1.8 \mathrm{~mm}$ relative to bregma and dural surface) and $2 \mu \mathrm{l}$ of solution containing both Alexa Fluor 488-labeled $\alpha$-syn monomers $(1 \mathrm{mg} / \mathrm{ml})$ and dynasore $(80 \mu \mathrm{M})$ in the right cortex (coordinates, AP: $1 \mathrm{~mm}$; ML: $-2.5 \mathrm{~mm}$; DV: $-1.8 \mathrm{~mm}$ relative to bregma and dural surface).

\section{Grafting procedure}

The ventral mesencephalon (VM) was dissected from E12.5 C57BL/6 mice in cold HBSS-Ca ${ }^{2+} / \mathrm{Mg}^{2+}$ as previously described (42). The VM pieces were incubated in HBSS-Ca ${ }^{2+} / \mathrm{Mg}^{2+}$ (Invitrogen) containing $0.1 \%$ trypsin and $0.05 \%$ DNase for 15 minutes at $37^{\circ} \mathrm{C}$. After rinsing, the VM tissues were mechanically dissociated into a single-cell suspension. The number of viable cells was estimated based on Trypan blue (Sigma-Aldrich) exclusion. After centrifugation $\left(180 \mathrm{~g}, 10\right.$ minutes, $\left.4^{\circ} \mathrm{C}\right)$, the supernatant was removed and the volume was adjusted to give a suspension of $0.5 \times 10^{5}$ viable cells $/ \mu \mathrm{l}$ in HBSS-Ca ${ }^{2+} / \mathrm{Mg}^{2+}$. The cells were stored on ice during the transplantation procedure. Each 6-week-old huo-syn-expressing mouse received 100,000 cells in $2 \mu \mathrm{l}$ via a Hamilton syringe (coordinates, AP: 0.5 $\mathrm{mm}$; ML: $-2.0 \mathrm{~mm}$; DV: $-3.0 \mathrm{~mm}$ relative to bregma and dural surface).

\section{Immunohistochemistry, microscopy, and quantification}

One day after injection of Alexa Fluor 488-labeled recombinant $\alpha$-syn or 6 months after grafting, mice were anesthetized with sodium pentobarbitone and perfused transcardially with $0.9 \%$ saline followed by $4 \%$ PFA in phosphate buffer. Six hours after the injection of Alexa Fluor 488-labeled recombinant $\alpha$-syn monomers with or without dynasore, rats were perfused using the same protocol as for mice. Brains were removed and postfixed in PFA for 24 hours before being placed in $20 \%$ sucrose until sectioning. 30 - and 40-micrometer-thick free-floating coronal sections, respectively, for mouse and rat brains, were cut on a freezing microtome and immunostained with primary antibodies against TH (raised in rabbit, 1:1000; Pel-Freez) and/or a specific antibody to hu- $\alpha$ syn (raised in mouse, 1:1000; Abcam), or to MAP2 (raised in mouse, 1:500; Sigma-Aldrich). For detection of TH antibody with the chromogen 3,3'-diaminobenzidine (DAB), sections were incubated in bio- tinylated goat anti-rabbit serum (1:200; Vector Laboratories) and then processed for a standard peroxidase-based method (Vectastain ABC kit and DAB kit; Vector Laboratories). For immunofluorescence staining, Cy3-conjugated anti-mouse and Cy2-conjugated anti-rabbit sera (raised in donkey, 1:200; Jackson Immunoresearch Laboratories) were used. Specimen analyses were performed either with a conventional epifluorescence microscope (Eclipse 80i microscope; Nikon) or with a confocal microscope as described above.

For quantification of the mean Alexa Fluor 488 fluorescence after injection of Alexa Fluor 488-labeled $\alpha$-syn monomers with or without dynasore in the rat brain, we used Image (NIH) to define an area of interest around the injection site, based on the edges of the brightest Alexa Fluor 488 fluorescence. Although the sizes of the areas of interest were comparable across all animals, we normalized the mean Alexa Fluor 488 fluorescence measured in the areas of interest with the corresponding surface areas (expressed in arbitrary area unit). Then we compared the mean Alexa Fluor 488 fluorescence in the presence or in the absence of dynasore using Student's $t$ test, defining $P<0.01$ as significant.

\section{Procedure for enhancement of signal and making $3 D$ rotations}

The software programs Improvision Volocity 5.3.2 and Adobe Photoshop CS4 were used for generation of 3D rotations from confocal microscopy pictures of neurons. First, in Volocity, the original lsm stacks were opened and saved as individual Tiff series. Next, in Photoshop, all images were then converted to 8-bit grayscale, subjected to Median filtering to remove shot noise while respecting boundaries, and saved in PS format. An adjustment layer (levels) was made for each image, to enhance visualization of signal.

Red channel ( $\alpha-s y n)$ and green channel (GFP). Levels were adjusted in the adjustment layer so that the signal dynamic range spanned 256 gray levels. Structures seen in red channel were enhanced using the eraser tool at opacity $20 \%$ and flow $25 \%$. With respect to the green channel, the GFP signal was "smoothed" using the brush tool at brightness $25 \%$ and opacity $25 \%$. Adjustment layers were discarded, leaving the individual images with the original dynamic range but enhanced structures of interest. Images were saved as tiff files. Next, the processed tiff series were imported to Volocity and opened as an image sequence with original color channels and scan parameters restored. The volume was cropped (free hand) as close to the cell of interest as possible. 3D projections were made and saved as Supplemental Videos 1 and 2. The videos were exported as QuickTime movie clips.

\section{Acknowledgments}

We thank Nikki Jane Damsgaard, Darren Cleare, Britt Lindberg, and Birgit Haraldsson for excellent technical assistance. We are grateful to Peter Ekström (ImaGene-IT, Lund) for his expert help with the $3 \mathrm{~S}$ reconstructed rotating images. This work was supported by the Swedish Research Council, the Human Frontier Science Program, ERA-Net NEURON - MIPROTRAN, the Swedish Brain Foundation, the Parkinson Foundation (Sweden), the Söderberg Foundation, the Michael J. Fox Foundation for Parkinson's Research, the Nordic Center of Excellence on Neurodegeneration, Stiftelsen Lars Hiertas Minne, Knut och Alice Wallenbergs stiftelse, a donation from Sven Astell, the Centre National de la Recherche Scientifique, and the Agence Nationale de la Recherche.

Received for publication August 2, 2010, and accepted in revised form November 17, 2010.

Address correspondence to: Patrik Brundin, Neuronal Survival Unit, Wallenberg Neuroscience Center, Lund University, BMC A10, 22184 Lund, Sweden. Phone: 46.46.222.05.29; Fax: 46.46.222.05.31; E-mail: patrik.brundin@med.lu.se. 
1. Spillantini MG, Schmidt ML, Lee VM, Trojanowski JQ, Jakes R, Goedert M. Alpha-synuclein in Lewy bodies. Nature. 1997;388(6645):839-840.

2. Jakes R, Spillantini MG, Goedert M. Identification of two distinct synucleins from human brain. FEBS Lett. 1994;345(1):27-32.

3. Norris EH, Giasson BI, Lee VM. Alpha-synuclein: normal function and role in neurodegenerative diseases. Curr Top Dev Biol. 2004;60:17-54.

4. Burre J, Sharma M, Tsetsenis T, Buchman V, Etherton MR, Sudhof TC. Alpha-synuclein promotes SNARE-complex assembly in vivo and in vitro. Science. 2010;329(5999):1663-1667.

5. Kruger R, et al. Ala30Promutation in the gene encoding alpha-synuclein in Parkinson's disease. Nat Genet. 1998;18(2):106-108.

6. Polymeropoulos MH, et al. Mutation in the alphasynuclein gene identified in families with Parkinson's disease. Science. 1997;276(5321):2045-2047.

7. Zarranz JJ, et al. The new mutation, E46K, of alphasynuclein causes Parkinson and Lewy body dementia. Ann Neurol. 2004;55(2):164-173.

8 . Fuchs J, et al. Phenotypic variation in a large Swedish pedigree due to SNCA duplication and triplication. Neurology. 2007;68(12):916-922.

9. Singleton AB, et al. alpha-Synuclein locus triplication causes Parkinson's disease. Science. 2003; 302(5646):841.

10. Kordower JH, Chu Y, Hauser RA, Freeman TB, Olanow CW. Lewy body-like pathology in long-term embryonic nigral transplants in Parkinson's disease. Nat Med. 2008;14(5):504-506.

11. Li JY, et al. Lewy bodies in grafted neurons in subjects with Parkinson's disease suggest host-to-graft disease propagation. Nat Med. 2008;14(5):501-503.

12. Li JY, et al. Characterization of Lewy body pathology in 12- and 16-year-old intrastriatal mesencephalic grafts surviving in a patient with Parkinson's disease. Mov Disord. 2010;25(8):1091-1096.

13. Braak H, Del Tredici K, Rub U, de Vos RA, Jansen Steur EN, Braak E. Staging of brain pathology related to sporadic Parkinson's disease. Neurobiol Aging. 2003;24(2):197-211.

14. Angot E, Brundin P. Dissecting the potential molecular mechanisms underlying alpha-synuclein cell-to-cell transfer in Parkinson's disease. Parkinsonism Relat Disord. 2009;15 suppl 3:S143-S147.

15. Angot E, Steiner JA, Hansen C, Li JY, Brundin P. Are synucleinopathies prion-like disorders? Lancet
Neurol. 2010;9(11):1128-1138.

16. Brundin P, Melki R, Kopito R. Prion-like transmission of protein aggregates in neurodegenerative diseases. Nat Rev Mol Cell Biol. 2010;11(4):301-307.

17. Frost B, Diamond MI. Prion-like mechanisms in neurodegenerative diseases. Nat Rev Neurosci. 2010; 11(3):155-159.

18. Goedert M, Clavaguera F, Tolnay M. The propagation of prionlike protein inclusions in neurodegenerative diseases. Trends Neurosci. 2010; 33(7):317-325

19. Borghi R, et al. Full length alpha-synuclein is present in cerebrospinal fluid from Parkinson's disease and normal subjects. Neurosci Lett. 2000;287(1):65-67.

20. El-Agnaf OM, et al. Alpha-synuclein implicated in Parkinson's disease is present in extracellular biological fluids, including human plasma. FASEB J. 2003;17(13):1945-1947.

21. El-Agnaf OM, et al. Detection of oligomeric forms of alpha-synuclein protein in human plasma as a potential biomarker for Parkinson's disease. FASEBJ 2006;20(3):419-425.

22. Tokuda T, et al. Decreased alpha-synuclein in cerebrospinal fluid of aged individuals and subjects with Parkinson's disease. Biochem Biophys Res Com mun. 2006;349(1):162-166.

23. Lee HJ, Patel S, Lee SJ. Intravesicular localization and exocytosis of alpha-synuclein and its aggregates. J Neurosci. 2005;25(25):6016-6024.

24. Emmanouilidou E, et al. Cellproduced alpha-synuclein is secreted in a calcium-dependent manner by exosomes and impacts neuronal survival. J Neurosci. 2010;30(20):6838-6851

25. Lee HJ, Suk JE, Bae EJ, Lee JH, Paik SR, Lee SJ. Assembly-dependent endocytosis and clearance of extracellular alphasynuclein. Int J Biochem Cell Biol. 2008;40(9):1835-1849.

26. Desplats $P$, et al. Inclusion formation and neuronal cell death through neuron-to-neuron transmission of alphasynuclein. Proc Natl Acad Sci U S A. 2009; 106(31):13010-13015.

27. Outeiro TF, et al. Formation of toxic oligomeric alpha-synuclein species in living cells. PLoS One. 2008; 3(4):e1867.

28. Brundin P, Li JY, Holton JL, Lindvall O, Revesz T. Research in motion: the enigma of Parkinson's disease pathology spread. Nat Rev Neurosci. 2008; 9(10):741-745

29. Aguzzi A, Rajendran L. The transcellular spread of cytosolic amyloids, prions, and prionoids. Neuron. 2009;64(6):783-790.

30. Braak H, Del Tredici K, Bratzke H, Hamm-Clement J, Sandmann-Keil D, Rub U. Staging of the intracerebral inclusion body pathology associated with idiopathic Parkinson's disease (preclinical and clinical stages). J Neurol. 2002;249(1):1-5.

31. Luk KC, et al. Exogenous alpha-synuclein fibrils seed the formation of Lewy body-like intracellular inclusions in cultured cells. Proc Natl Acad SciUS A. 2009;106(47):20051-20056.

32. Danzer KM, Krebs SK, Wolff M, Birk G, Hengerer B. Seeding induced by alpha-synuclein oligomers provides evidence for spreading of alpha-synuclein pathology. J Neurochem. 2009;111(1):192-203.

33. Balch WE, Morimoto RI, Dillin A, Kelly JW. Adapting proteostasis for disease intervention. Science. 2008;319(5865):916-919.

34. Chu Y, Kordower JH. Lewy body pathology in fetal grafts. Ann N Y Acad Sci. 2010;1184:55-67.

35. Sinclair SR, Fawcett JW, Dunnett SB. Dopamine cells in nigral grafts differentiate prior to implantation. Eur J Neurosci. 1999;11(12):4341-4348.

36. Ren PH, Lauckner JE, Kachirskaia I, Heuser JE, Melki R, Kopito RR. Cytoplasmic penetration and persistent infection of mammalian cells by polyglutamine aggregates. Nat Cell Biol. 2009; 11(2):219-225.

37. Frost B, Jacks RL, Diamond MI. Propagation of tau misfolding from the outside to the inside of a cell. J Biol Chem. 2009;284(19):12845-12852.

38. Clavaguera F, et al. Transmission and spreading of tauopathy in transgenic mouse brain. Nat Cell Biol. 2009;11(7):909-913.

39. Westerlund M, et al. Lrrk2 and alpha-synuclein are co-regulated in rodent striatum. Mol Cell Neurosci. 2008;39(4):586-591.

40. Ghee M, Melki R, Michot N, Mallet J. PA700, the regulatory complex of the $26 \mathrm{~S}$ proteasome, interferes with alpha-synuclein assembly. FEBS J. 2005; 272(16):4023-4033.

41. McParland VJ, et al. Partially unfolded states of beta(2)-microglobulin and amyloid formation in vitro. Biochemistry. 2000;39(30):8735-8746.

42. Dunnett SB, Björklund A. Dissecting embryonic neural tissues for transplantation. In: Dunnett SB, Boulton AA, Baker GB, eds. Neuromethods: Cell and Tissue Transplantation in the CNS. New York, New York, USA: Humana Press; 2000:3-25. 